\title{
Seasonal Changes in Avian Song Nuclei without Seasonal Changes in Song Repertoire
}

\author{
Eliot A. Brenowitz,, ${ }^{1,2}$ Belinda Nalls, ${ }^{1}$ John C. Wingfield, ${ }^{2}$ and Donald E. Kroodsma ${ }^{3}$ \\ 'Departments of Psychology and 'Zoology, University of Washington, Seattle, Washington 98195, and ${ }^{3}$ Department of \\ Zoology, University of Massachusetts, Amherst, Massachusetts 01003-0027
}

\begin{abstract}
Seasonal variation in the size of song nuclei in the brains of male songbirds may be related to the ability to learn to sing new songs as adults. This hypothesis was tested with the rufous-sided towhee (Pipilo erythrophthalmus), a species in which song repertoires are stable after $1 \mathrm{yr}$ of life. Towhees were hand raised in the laboratory and tutored with normal towhee songs. After song repertoires were recorded at $1 \mathrm{yr}$ of age, photoperiods were manipulated so that 10 male towhees experienced short days and 10 males experienced long days. Circulating hormone concentrations and anatomical attributes of song nuclei were then measured. Photoperiodrelated differences in the song nuclei of these towhees were as large as those seen in "open-ended learners" (i.e., species that continue to learn new songs as adults). Seasonal changes of the adult song system may thus occur without disrupting existing song repertoires and without the development of new songs. The synaptic plasticity provided by such seasonal variation, however, may enable song learning by adult birds.
\end{abstract}

In temperate and subtropical bird species, reproduction is seasonal, with breeding generally restricted to the spring and early summer. In oscine birds, song behavior is a critical feature of reproduction. Song acts in the contexts of territorial defense and courtship and, together with other reproductive behaviors, is seasonal in occurrence. It is produced most frequently early in the breeding season, when birds establish territories and attempt to attract and stimulate mates. Song is produced much less often outside of the breeding season.

In songbirds, song production is controlled by a network of discrete brain nuclei (reviewed by Nottebohm, 1987; Konishi, 1989). Of main importance in the motor control of song are the caudal nucleus of the ventral hyperstriatum (HVc) and its efferent target, the robust nucleus of the archistriatum (RA). RA projects to the hypoglossal nucleus (nXII) in the hindbrain. The muscles of the syrinx, the sound-producing organ, are inner-

\footnotetext{
Received Aug. 31, 1990; revised Dec. 4, 1990; accepted Dec. 26, 1990.

We thank Nedil Aldorando for analyzing tape recordings, Iinda Crane for perfusing the birds, Lynn Erckman for performing the hormone assays, David Ewert for help in finding nests, and Melissa Kroodsma for overseeing the hand rearing of the birds. Arthur Amold, Patricia Loesche, Fernando Nottebohm, David Spector, and two anonymous referees made helpful comments on the manuscript. This research was supported by NIH Grant DC 00487 , by an Alfred P. Sloan research fellowship, by a University of Washington Graduate School Research Fund grant to E.A.B., and by National Science Foundation Grants BNS 8506996 and 8812084 to D.E.K. and DCB 8616155 to J.C.W.

Correspondence should be addressed to E. A. Brenowitz, Department of Psychology NI-25, University of Washington, Seattle, WA 98195.

Copyright (C) 1991 Society for Neuroscience $0270-6474 / 91 / 111367-08 \$ 03.00 / 0$
}

vated by motor neurons from the tracheosyringeal portion of nXII. HVc also projects to area X in the parolfactory lobe of the forebrain. Different regions of the magnocellular nucleus of the anterior neostriatum (MAN) project to HVc and RA. Both area $\mathrm{X}$ and MAN are essential for song learning (Bottjer et al., 1984; Scharf and Nottebohm, 1989; Sohrabji et al., 1990; Suter et al., 1990). Neurons in HVc, RA, MAN, and nXII accumulate testosterone $(\mathrm{T})$ or its estrogenic and reduced androgenic metabolites (Arnold et al., 1976, 1986; Gahr et al., 1987; Brenowitz and Arnold, 1989).

Song must be learned in oscine birds (reviewed by Marler and Peters, 1982; Nottebohm, 1987; Bohner et al., in press). Considerable variation among species exists in the timing of song learning, but two general developmental patterns emerge: In "age-limited" species (Marler and Peters, 1987), such as the zebra finch (Poephila guttata; Eales, 1985) and the white-crowned sparrow (Zonotrichia leucophrys; Marler, 1970; Cunningham and Baker, 1983; Petrinovich and Baptista, 1987), song learning is usually restricted to the first year of life. In "open-ended" species, such as the canary (Serinus canarius; Nottebohm and Nottebohm, 1978) and the red-winged blackbird (Agelaius phoeniceus; Marler et al., 1972; D. E. Kroodsma, unpublished observations), substantial song learning continues into the second year and potentially beyond.

The best-studied open-ended learner is the canary (reviewed by Nottebohm, 1987). At the end of the breeding season, song becomes plastic in structure; some song syllables are deleted, and others are modified or added. By the start of the next breeding season, song becomes stable again. A net increase in repertoire size occurs between successive breeding seasons.

Seasonal changes in male canary song behavior correlate with seasonal changes in circulating $T$ levels. The postbreeding period of plastic song coincides with low circulating $T$ levels (Nottebohm et al., 1987). The modification and addition of song syllables reaches its maximum when $\mathrm{T}$ levels start to rise after being low for several weeks.

The ability of male canaries to modify song in successive adult years suggests that there is plasticity in the neural substrate underlying song behavior. Nottebohm (1981) found that HVc and RA in male canaries, measured in Nissl-stained sections, decrease after the breeding season to only $50 \%$ and $56 \%$, respectively, of their volumes during breeding. He hypothesized that the shrinkage in the fall results in the "forgetting" of song syllables as dendrites retract and synapses are disrupted. According to this model, dendrites grow, new synapses are formed, and males learn to produce new song syllables in the spring. Seasonal changes in circulating $T$ levels may be the proximate 
mechanism for seasonal changes in song nuclei (Nottebohm et al., 1987), given that exogenous $T$ induces dendritic growth and synaptogenesis in adult female canary RA (DeVoogd and Nottebohm, 1981; DeVoogd et al., 1985).

This model of seasonal change in male canary song nuclei was extended by Gahr (1990). He confirmed that HVc, as defined by Nissl stain, changed in size with seasons. Gahr found, however, that if the borders of HVc were defined by the distribution of neurons that projected to area $X$ and were labeled by a monoclonal antibody raised against the human estrogen (E) receptor, then there was no seasonal change in the size of this nucleus.

If seasonal changes in song nuclei are related to the learning and forgetting of a song repertoire each year, then it was predicted that such seasonal variation will not occur in the brains of age-limited song learners (Nottebohm, 1981, 1989). When we began our study (1987), this prediction had been tested for only one such species. Baker et al. (1984) did not observe seasonal changes in the volumes of HVc and RA in male whitecrowned sparrows, a species in which males sing only one song type. An adequate test of the proposed relationship between seasonal variation in song nuclei and adult song learning, however, requires that other age-limited (and open-ended) learners, in a variety of taxa, also be analyzed.

In the present study we asked if there are seasonal changes in the structure of song nuclei in an age-limited learning species, the rufous-sided towhee (Pipilo erythrophthalmus), in which males have sizeable repertoires of songs. This towhee is common in North America; breeding is seasonal, as is song behavior. Males defend breeding territories and use a repertoire of one to six song types (Ewert, 1978). The onset of song behavior in spring correlates with an increase in the number of Leydig cells (a major source of $T$ ) in the interstitial tissue of the testis. The termination of song behavior in summer correlates with gonadal regression (Davis, 1958). Ewert (1978) recorded the full song repertoires of 17 wild color-banded males in New York for two or more years and found no evidence that these towhees modified their song repertoires in successive adult years.

\section{Materials and Methods}

Subjects and housing conditions. As part of a study of song development (D. E. Kroodsma and D. N. Ewert, unpublished observations), 20 male towhees were collected as nestlings in either western (near Amherst) or eastern (near Plymouth and Buzzard's Bay) Massachusetts during the spring of 1987 . They were hand reared in the laboratory of one of us (D.E.K.). Eighteen of these birds were tutored with tapes of normal adult towhee song recorded in Massachusetts. Each bird heard its tutor tape of cight different towhee song types on $45 \mathrm{~d}$ during the hatching summer. Nine of the 18 birds were reared in isolation in individual sound chambers, and the other nine birds were reared in trios in three separate rooms. The remaining two birds were untutored and kept together in still another room. Birds from the three different rearing conditions (isolation tutored, social tutored, and untutored) were distributed between the long-day and short-day photoperiod groups in a balanced fashion.

All birds were kept on long-day photoperiods [light : dark cycle (L: D), 15:9 hr] through the summer of 1987. The photoperiod was then shifted gradually to a short-day schedule (L:D, 9:15 hr) and maintained there through January 31,1988 . To induce vernal song behavior, we gradually changed the photoperiod to $\mathrm{L}: \mathrm{D}, 15: 9 \mathrm{hr}$ during February and March and maintained it there until May 15, 1988.

After tape recording the songs of all males, we manipulated the photoperiod once again so that we could simulate spring and late fall seasons for our two experimental groups of same-age males. From May 15 to July 15,1988 , all birds were maintained on short days (L:D, 9:15 hr). To induce another reproductive cycle, we then placed 10 birds on long days (L:D, 15:9 hr) for 4 weeks from July 15 to August 14. The other 10 birds were kept on short days until August 14.

On August 14, when all birds were 15 months old, blood samples were collected from the alar vein of all birds for hormone analysis (see below). They were then anesthetized immediately with Metafane and perfused through the left ventricle of the heart with saline followed by $10 \%$ formalin. The brains and testes were removed and placed in neutral buffered formalin for at least 2 weeks.

Song behavior. Between January 31 and May 15, 1988, we made extensive recordings of the song repertoires of the 18 birds that received song tutoring as juveniles (nine birds per experimental group). A male's repertoire was considered to be sufficiently sampled when several examples of most syllable types were recorded, without new syllable types appearing in successive days. These recordings were analyzed on a Kay DSP sonagraph.

In both wild and hand-reared towhees, the overall duration of song and the sequence of song syllables may vary under situations of agonistic arousal, such as during vocal intcractions with other birds (Harding and Follet, 1979). The repertoire of song syllables, however, remains highly stereotyped for individual towhees. Estimates of repertoire size derived from counts of song syllables therefore reflect the vocal abilities of different birds more accurately than do estimates based on the number of song types (for a discussion of the comparability problem, see Kroodsma, 1982). Accordingly, we estimated repertoire size for each male as the number of different song syllables observed in the full sample of his recorded songs.

Hormone analysis. Blood samples were collected from the alar vein into heparinized capillary tubes immediately prior to death. Samples were centrifuged at $1000 \mathrm{rpm}$ for $5 \mathrm{~min}$, and the plasma was removed and stored at $-20^{\circ} \mathrm{C}$. Circulating concentrations of $\mathrm{T}$ and $17 \beta$-estradiol $\left(\mathrm{E}_{2}\right)$ were measured by radioimmunoassay (RIA) as in Wingfield and Farner (1975) and Ball and Wingfield (1987). Briefly, $2000 \mathrm{cpm}$ of each ${ }^{3} \mathrm{H}$-labeled steroid was used to equilibrate each plasma sample for later measurement of percentage recovery after chromatography. After samples were extracted in $5 \mathrm{ml}$ of dichloromethane, the dried extract was transferred to the top of microchromatography columns containing diatomaceous earth, propylene glycol, and ethylene glycol. Increasing concentrations of ethyl acetate in isooctane were used to elute each steroid fraction. Purified fractions were dried and taken up in phosphate-buffered saline with $2 \%$ gelatin and $2 \%$ sodium azide. Separate RIAs for each hormone were used to estimate the unknown hormone concentrations. Plasma levels of $T$ and $E_{2}$ are presented as nanograms per milliliter.

The testes of birds typically change in size dramatically with changes in photoperiod. We therefore measured the combined weight of both testes for each male after perfusion.

Neural attributes. We weighed the brains and embedded them in gelatin. The gelatin block was trimmed and placed in a $20 \%$ sucrose/ formalin solution for $48 \mathrm{hr}$. Transverse frozen sections were cut serially at a thickness of $50 \mu \mathrm{m}$ and collected into avian saline. Alternate sections were mounted and stained with thionin.

We measured the volumes of five song-control nuclei ( $\mathrm{HVc}, \mathrm{RA}$, area $X, M A N$, and $n X I I)$ and of three midbrain nuclei unrelated to vocal control [the rotund nucleus ( $\mathrm{Rt}$ ), the pretectal nucleus $(\mathrm{Pt})$, and the medial spiriform nucleus (SpM)]. Our measures of $\mathrm{HVc}$ included the caudalmost portion, which extends medially and ventrally along the ventricle and contains large, densely packed cells (Fig. 1). These measurements correspond to the "inclusive" measures of Kirn et al. (1989). In most birds, we were unable to distinguish separately the lateral and medial portions of MAN (Nottebohm et al., 1982) rcliably from the Nissl-stained sections (Fig. 2). We therefore measured the volume of the entire MAN for all birds. A magnified image of stained sections was projected on paper at $46 \times$, the perimeter of the relevant nucleus was traced, and the area was calculated using a digitizing tablet and microcomputer. We multiplied the area of each section by the sampling interval of $100 \mu \mathrm{m}$. To obtain the total volume for each nucleus, we summed the volumes of all individual sections taken through the nucleus for both sides of the brain. The observer was blind to treatment group for this procedure and for all other measurements.

Using a calibrated computerized image analysis system (Imaging Research, Inc.), we measured the area of somata of neurons in HVc, RA, area X, nXII, and Rt. To ensure that we examined only neurons of the target nucleus, we placed the visual field on the video monitor well within the Nissl-defined borders of each nucleus. The pcrimeters of individual neuronal cell bodies, viewed at a total microscopic magni- 


\section{Short day towhee}
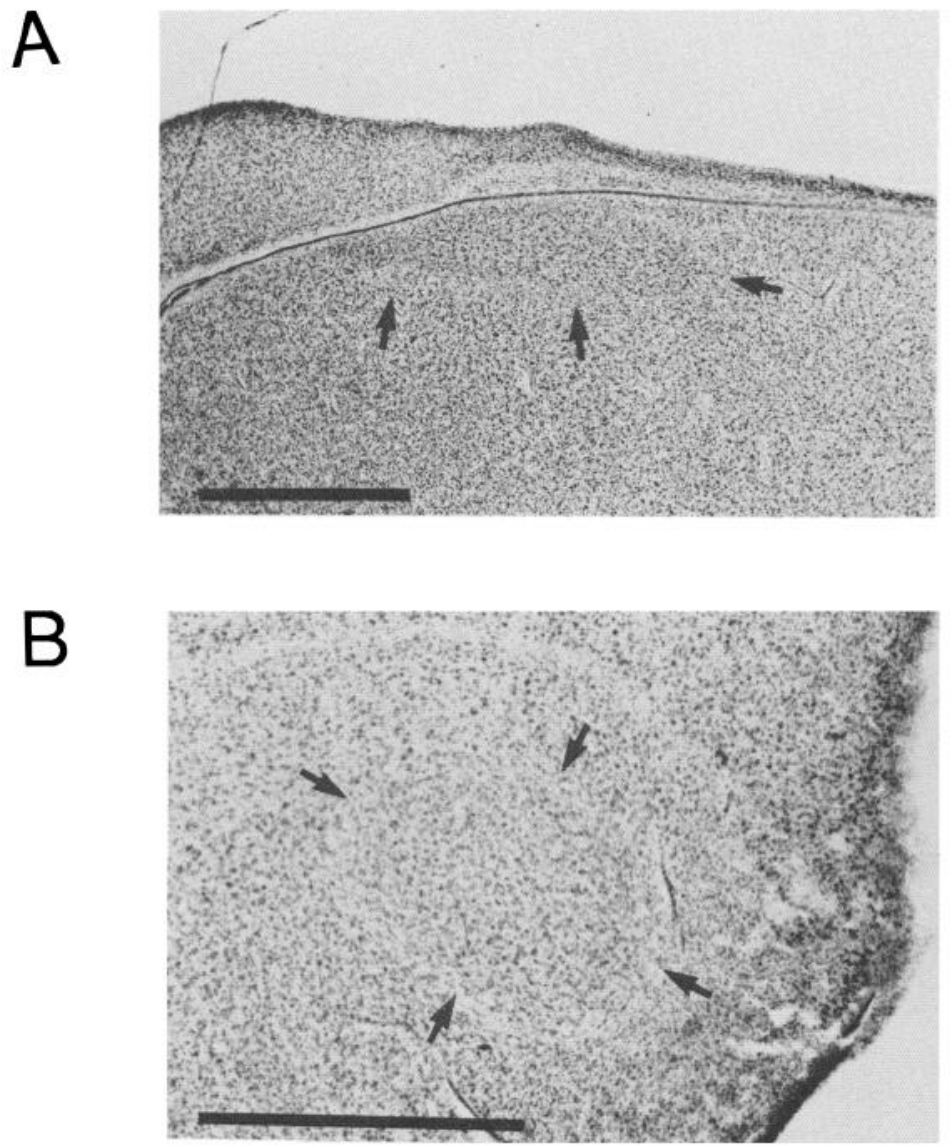

B
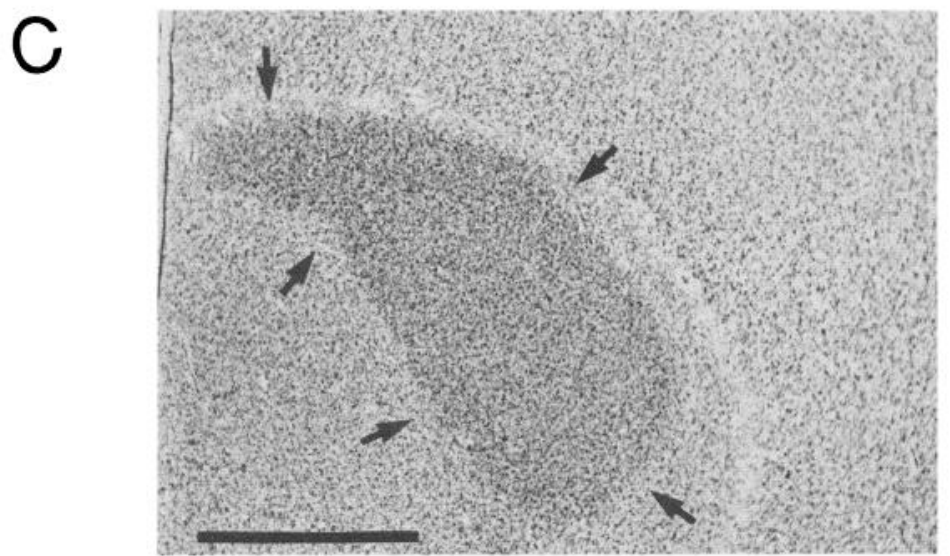

Figure 1. A, HVc in male rufous-sided towhees exposed to short-day (left) and long-day (right) photoperiods. Arrows indicate the Nissl-defined borders. Note that $\mathrm{HVc}$ in the short-day towhee does not extend medially as far as it does in the long-day towhee. $B$, RA in short-day and longday male towhees. Note the greater cell size in RA of the long-day bird. $C$, Area X in short-day and long-day towhees. Note the greater cell size in area $\mathrm{X}$ of the long-day bird. Maximum cross-sectional areas are shown for each nucleus. Scale bar, $1.0 \mathrm{~mm}$ for $A-C$.

fication of $250 \times$, were traced on screen with a computer mouse. The area of each outlined cell body was automatically determined by the imaging system.

In HVc, RA, and Rt, at least 100 neurons per individual were measured throughout the full extent of the median section of each nucleus

\section{Long day towhee}
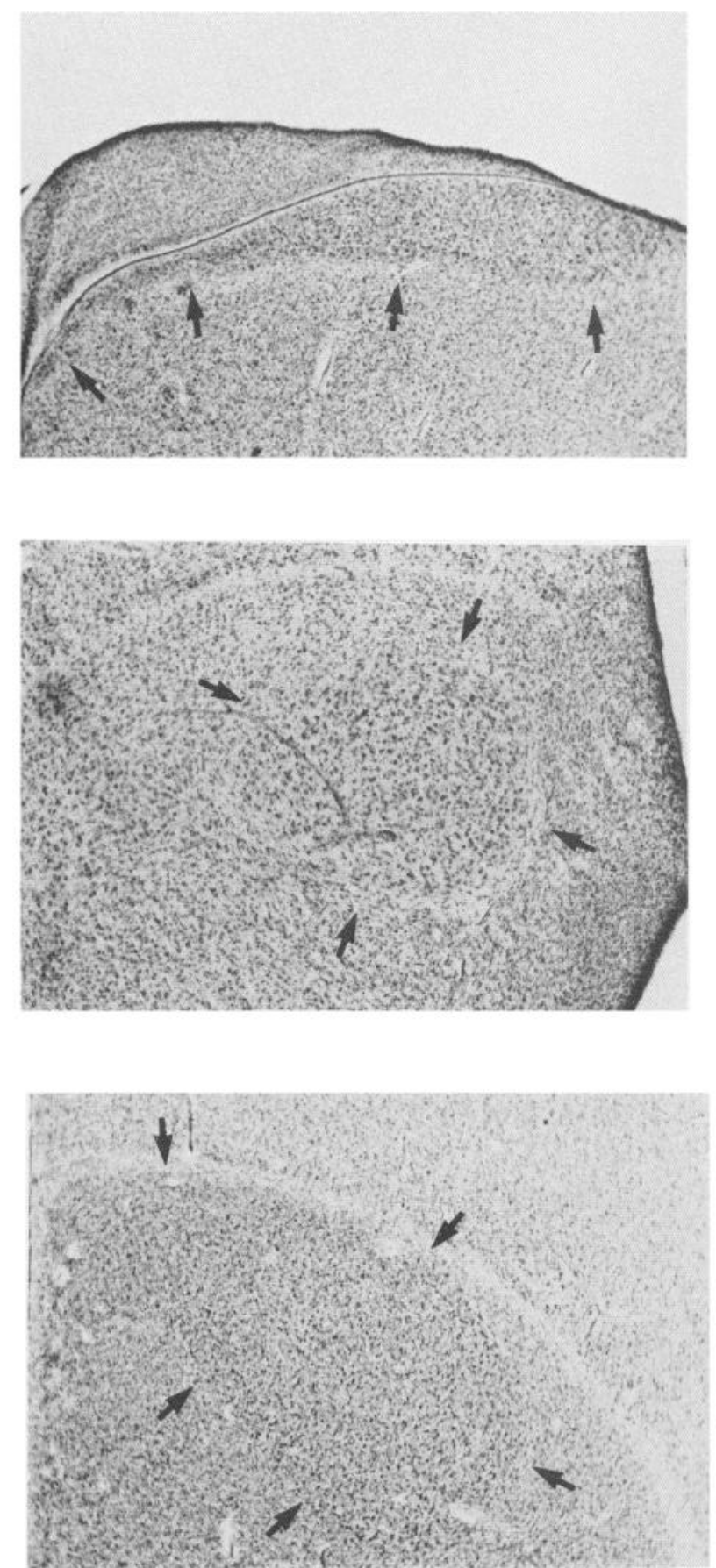

for five representative males from each of the two treatment groups. In area $\mathrm{X}$ and $\mathrm{nXII}$, at least 50 neurons per individual were measured for five representative males per group. The smaller number of neurons measured in these two nuclei reflects the selective sampling of large neurons in area X (see below) and the relatively small size of nXII. 


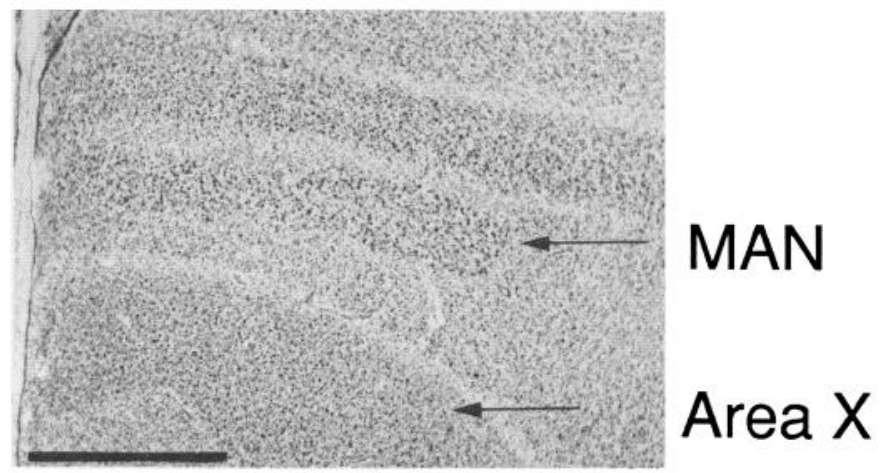

Figure 2. MAN in long-day male towhee. This nucleus did not differ in size between long-day and short-day towhees. MAN is shown in relation to position of area X. Scale bar, $1.0 \mathrm{~mm}$.

Cells with a relatively large soma, with a clear nucleus generally containing only one large, darkly stained nucleolus, and with a uniform, nongranular cytoplasm were judged to be neurons. Small cells that did not have a distinct nucleus, had multiple nucleoli, and had a granular cytoplasm were considered to be glia and were not measured. By these conservative criteria, small neurons may be interpreted falsely as glia. Our measures of neuronal density and number in song nuclei (below) may therefore be underestimates.

Area X contains cells of several different size and morphological classes in Nissl-stained sections, and we used a selective sampling procedure to ensure that we measured only neurons. We restricted our measures of neuron size, density, and number (see below) to the largest class of cells, which had somal areas on the order of $100-200 \mu \mathrm{m}^{2}$. This class of cells was qualitatively distinct from others in area $\mathrm{X}$ and could be identified unambiguously as consisting of neurons. Identification of the other cells in this nucleus as neurons was less certain.

Neuronal density was measured in HVc, RA, area X, and Rt by counting the number of neuronal nucleoli in a sample volume of 1.568 $\times 10^{-4} \mathrm{~mm}^{3}$ at a magnification of $1000 \times$. In HVc and RA, 10 such volumes per individual were sampled throughout different regions of each nucleus for all males. For area X, data were collected for 9 longday males and 10 short-day males; the histology did not permit accurate measurement of the size of area $\mathrm{X}$ for the remaining long-day male. We limited our measures of neuronal density in Rt to five males from each photoperiod group, because there was relatively low variance between males in this trait (see Fig. 5). Ten volumes per individual were sampled in Rt. Nucleoli were small relative to the section thickness of $50 \mu \mathrm{m}$, and we therefore made no correction for nucleolar splitting (Cammermeyer, 1967; Konigsmark, 1970).

The total numbers of neurons within the Nissl-defined borders of HVc, RA, area X, and Rt were estimated. We multiplied measures of neuronal density by the total volumes of these nuclei.

\section{Results}

Song behavior

The 18 song-tutored towhees produced many song syllables that were clear copies of what they had heard on the tutor tapes. The

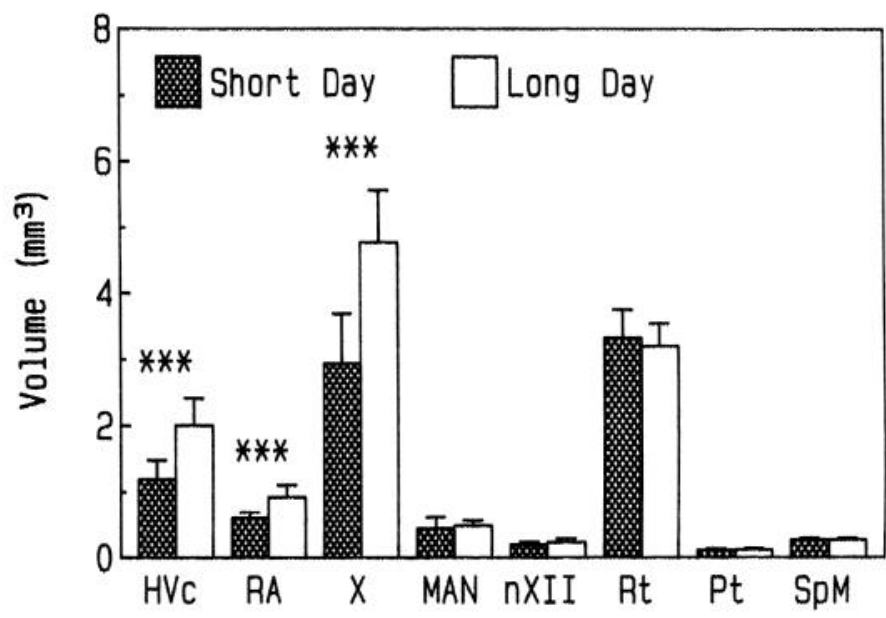

Figure 3. Volumes (right plus left, $\bar{x}+1 \mathrm{SD}$ ) of five brain nuclei involved in song behavior (HVc, RA, area X, MAN, and nXII) and of three nuclei not involved in song ( $\mathrm{Rt}, \mathrm{Pt}$, and $\mathrm{SpM}$ ) in towhee males exposed to short-day $(n=10)$ and long-day $(n=10)$ photoperiods. ${ }^{* * *}$, $p<0.001, t$ test.

males usually used their song syllables in highly stereotyped, repeatable sequences that were similar to wild towhee songs and that recurred from one day to the next. Full descriptions of song development in these birds will be presented at a later date (Kroodsma and Ewert, unpublished observations). Song repertoires of birds assigned to the long-day group did not differ in size from the repertoires of birds assigned to the short-day group (Table 1).

\section{Hormone analysis}

Our manipulations of photoperiod were highly effective at inducing the two groups of towhees into different physiological conditions. The combined weight of both testes was 50 times greater in long-day than in short-day towhees (Table 1). Circulating $\mathrm{T}$ levels were greater in long-day than in short-day males (Table 1). $E_{2}$ levels, however, did not differ between longday and short-day males (Table 1).

\section{Neural attributes}

The photoperiods that we used did not alter overall brain size. Brain weight did not differ between long-day and short-day birds (Table 1).

In both long-day and short-day towhees, the borders of the brain regions sampled in this study were well defined in Nisslstained sections (Fig. 1). The perimeter of MAN was easily

Table 1. Measures of behavioral, hormonal, and gross structural attributes in long-day and short-day towhees $(\tilde{x} \pm \mathbf{S D})$

\begin{tabular}{llcc} 
& Long day & Short day & Ratio \\
\hline Song repertoire (number of syllables) $^{a}$ & $14.9 \pm 4.7(8-22)$ & $15.6 \pm 7.2(8-28)$ & 0.96 \\
Testes weight $(\mathrm{mg})^{\text {Testosterone }(\mathrm{ng} / \mathrm{ml})}$ & $180 \pm 70$ & $3.6 \pm 0.9$ & $50^{* * *}$ \\
Estradiol $(\mathrm{ng} / \mathrm{ml})$ & $4.51 \pm 3.11$ & $0.31 \pm 0.19$ & $14.5^{* *}$ \\
Brain weight $(\mathrm{gm})$ & $0.54 \pm 0.65$ & $0.31 \pm 0.28$ & 1.76 \\
& $1.37 \pm 0.18$ & $1.40 \pm 0.06$ & 0.98
\end{tabular}

${ }^{a}$ Range for song repertoires is shown in parentheses.

${ }^{* *}, p<0.01$ ( $t$ test on absolute data); ***, $p<0.001$ 


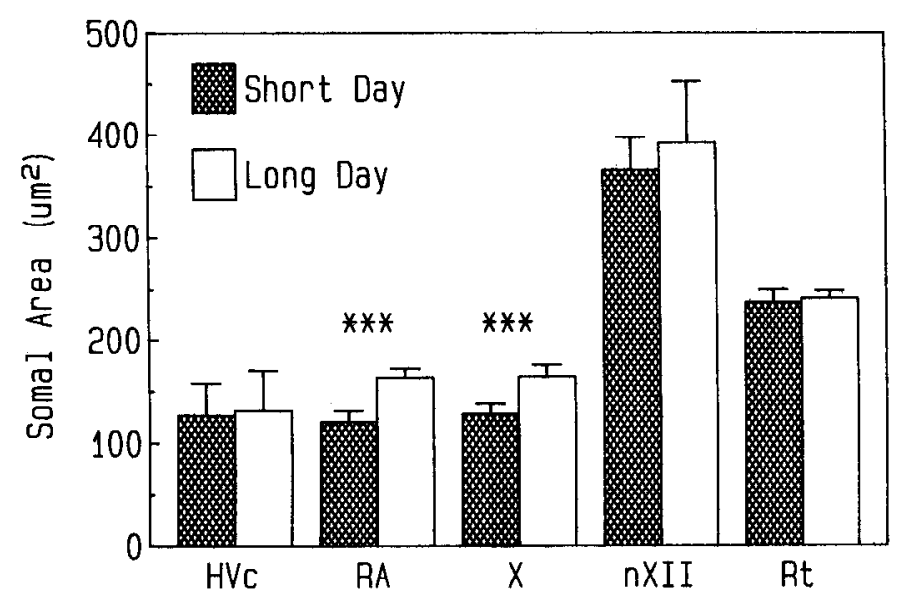

Figure 4. Somal area $(\bar{x}+1 \mathrm{SD})$ of neurons in four song nuclei (HVc, $R A$, area $X$, and $n X I I)$ and one nucleus not involved in song behavior (Rt) in towhee males exposed to short-day $(n=5)$ and long-day $(n=$ 5) photoperiods. ${ }^{* * *}, p<0.001, t$ test.

distinguished in towhee brains, unlike that of several other species studied (Fig. 2; E. A. Brenowitz, unpublished observations).

$\mathrm{HVc}, \mathrm{RA}$, and area $\mathrm{X}$ were larger in long-day than in shortday birds (Figs. 1, 3; Table 2). MAN, nXII, Rt, Pt, and SpM did not differ in volume between treatment groups (Fig. 3, Table 2).

In the nine long-day towhees, there was no correlation between song repertoire size (number of syllable types) and the volumes of either HVc $(r=0.06 ; p=0.88)$ or $\mathrm{RA}(r=0.26 ; p$ $=0.50$ ). No correlation was evident for short-day towhees, either (HVc: $r=0.13 ; p=0.73$; RA: $r=-0.23 ; p=0.56$ ).

We also asked whether there were photoperiod-related changes in the size, spacing, or number of neurons in brain nuclei. In three nuclei (HVc, nXII, and Rt), we found no difference between long-day and short-day birds in the somal area of neurons (Fig. 4, Table 2). In two other nuclei (RA and area X), somal area was greater for long-day than for short-day birds (Fig. 4, Table 2).

The density of neurons in HVc and Rt did not differ between the treatment groups (Fig. 5, Table 2). In area $X$ there was no difference between the two photoperiod groups in the density of the subpopulation of large neurons that we sampled. Neuronal density in RA was less for long-day birds than for short-day towhees.

Long-day towhees had more neurons within the Nissl-defined borders of HVc and area X than did short-day birds (Fig. 6, Table 2). Neuronal number did not differ between treatment groups in RA and Rt.

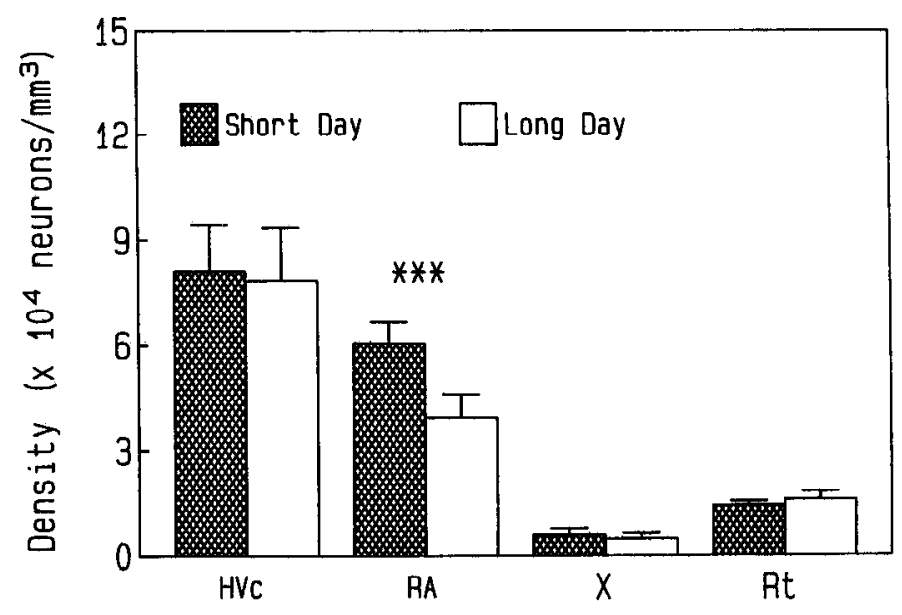

Figure 5. Density $(\bar{x}+1 \mathrm{SD})$ of neurons in three song nuclei (HVc, $R A$, and area $X)$ and one nucleus not involved in song behavior (Rt) in towhee males exposed to short-day and long-day photoperiods. Sample sizes: HVc and RA, $n=10$ males per photoperiod group; area $\mathrm{X}$, $n=9$ long-day and 10 short-day birds; Rt, $n=5$ males per group. ${ }^{* * *}$, $p<0.001, t$ test.

\section{Discussion}

\section{Size of song nuclei}

Exposure to long-day versus short-day photoperiods for 1 month produced dramatic differences in the size of three song nuclei (HVc, RA, and area X), as defined by Nissl stain, in the forebrains of towhee males. The magnitude of these differences is comparable to that reported for the canary (Nottebohm, 1981). Regions of towhees' brains not involved in song production did not differ in size between the photoperiod treatment groups.

These differences in the size of song nuclei observed between long-day and short-day towhees cannot be explained by differences in song repertoire size, because the mean number of song syllables produced in repertoires did not differ between groups. Also, as has been reported for red-winged blackbirds (Kirn et al., 1989), there was no correlation between song repertoire size and the volumes of HVc or RA. The results for towhees and blackbirds differ from those for canarics and marsh wrens ( $\mathrm{Cis}$ tothorus palustris), however, in which correlations between song repertoire size and the volume of song nuclei have been reported (Nottebohm et al., 1981; Canady et al., 1984). These observations may reflect true species differences in the encoding of song by brain nuclei, or may result from methodological differences between studies, such as how song repertoires and/or song nuclei were measured. Additional research is needed to resolve this issue.

The observed differences in the size of song nuclei between long-day and short-day towhees cannot be attributed to differ-

Table 2. Long day to short day ratios for neural attributes

\begin{tabular}{lllllllll} 
& HVc & RA & Area X & MAN & nXII & Rt & Pt & SpM \\
\hline Volume & $1.68^{* * *}$ & $1.54^{* * *}$ & $1.62^{* * *}$ & 1.01 & 1.19 & 0.96 & 1.07 & 1.01 \\
Somal area & 1.04 & $1.36^{* * *}$ & $1.28^{* * *}$ & & 1.07 & 1.02 & & \\
Neuron density & 1.03 & $0.65^{* * *}$ & 0.80 & & & 1.12 & & \\
Neuron number & $1.62^{* *}$ & 0.98 & $1.33^{*}$ & & & 1.14 & & \\
\hline
\end{tabular}

${ }^{*}, p<0.05 ;{ }^{* *}, p<0.01 ;{ }^{* * *}, p<0.001$ ( $t$ tests performed on absolute data). 


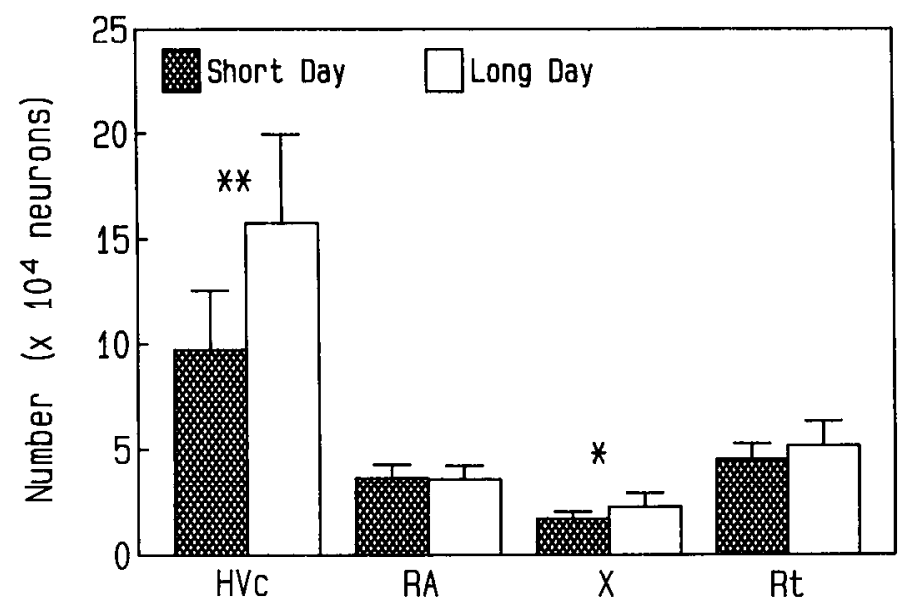

Figure 6. Total number $(\bar{x}+1 \mathrm{SD})$ of neurons estimated in three song nuclei (HVc, RA, and area $\mathrm{X}$ ) and one nucleus not involved in song behavior (Rt) in towhee males exposed to short-day and long-day photoperiods. Sample sizes are same as in Figure 5. ${ }^{*}, p<0.05 ;{ }^{* *}, p<$ $0.01 ; t$ test.

ences in overall brain size, because total brain weight did not differ between groups. In this respect, the towhees differed from laboratory-reared canaries, wild female red-winged blackbirds, and laboratory-reared male blackbirds. In these groups (but not in wild male blackbirds), individual brain weight increased up to $15 \%$ during the breeding season (Nottebohm, 1981; Kirn et al., 1989).

Of the forebrain song nuclei measured, only MAN did not differ in size between long-day and short-day towhees. The lateral portion of MAN by itself did not differ in volume between five long-day and four short-day towhees in which we could reliably measure just this part of the nucleus. MAN plays an important role in juvenile song learning by male zebra finches (Bottjer et al., 1984) and in seasonal song learning by adult male canaries (Suter et al., 1990). The lack of seasonal size change in towhee MAN may be related to the absence of adult song learning in this species. A comparison of seasonal variation in the structure and effect of lesions of MAN between age-limited and open-ended song learning species would help to resolve this issue. We know of no published data on seasonal measurements of MAN in any other species.

\section{Cellular attrihutes of song nuclei}

The cellular attributes associated with the photoperiod-related changes in volumes differed among the song nuclei. We will therefore discuss the cellular attributes separately for $\mathrm{HVc}, \mathrm{RA}$, and area $\mathrm{X}$.

The increased volume of $\mathrm{HVc}$ in long-day towhees compared to short-day towhees was accompanied by an increase in the number of neurons within the Nissl-defined borders of this nucleus. The size and spacing of neurons in HVc did not change with photoperiod. From the present data, we cannot determine whether the increased number of neurons resulted from neurogenesis, cell migration, or a photoperiod-related change in the Nissl-staining characteristics of HVc neurons. Newly generated neurons are recruited into canary $\mathrm{HVc}$ year round (Nottebohm, 1985; Alvarez-Buylla et al., 1990). Whereas the borders of canary $\mathrm{HVc}$ vary with season when defined by Nissl staining, this nuclcus remains constant in size when defined by the distribution of $\mathrm{E}$ receptor-containing neurons that project to area $\mathrm{X}$

$\begin{aligned} & \text { Table 3. Comparison of five songbird species in which seasonal } \\
& \text { variation of song attributes has been studied }\end{aligned}$
\begin{tabular}{lllc} 
& $\begin{array}{l}\text { Seasonal } \\
\text { changes in } \\
\text { song nuclei }\end{array}$ & $\begin{array}{l}\text { Open-ended learner } \\
\text { lepertoire } \\
\end{array}$ & $\begin{array}{l}\text { Song } \\
\text { size }\end{array}$ \\
\hline White-crowned sparrow $^{a}$ & - & - & 1 \\
Red-winged blackbird $^{b}$ & + & + & $>1$ \\
Canary $^{c}$ & + & + & $>1$ \\
Orange bishop $^{d}$ & + & - & 1 \\
Rufous-sided towhee & + & - & $>1$
\end{tabular}

+ or - indicates presence or absence, respectively, of a trait.

a Data are from Baker et al. (1984).

${ }^{b}$ Data are from Kirn et al. (1989).

c Data are from Nottebohm (1981).

${ }^{`}$ Data are from Arai ei al. (1989).

(Gahr, 1990) or the distribution of RA-projecting neurons (F. Nottebohm, personal communication). Even if the ovirall volume of $\mathrm{HVC}$ does not change seasonally, however, these results suggest that there is a fundamental seasonal change in at least one subpopulation of neurons that is reflected in differences in staining properties.

Associated with the increased size of RA in long-day towhees was an increase in the size of neurons and a resulting decrease in their density. This increase in neuronal size may be a direct consequence of the increased circulating levels of $\mathrm{T}$ in the longday birds. Increased $T$ levels produce dendritic growth of RA neurons in adult female canaries (DeVoogd and Nottebohm, 1981).

The heterogeneous cellular composition of area $\mathrm{X}$ makes it difficult to sample all neurons reliably from Nissl-stained sections alone. For this reason, we restricted our analysis of this nucleus to the largest class of cells, which we could identify unambiguously as consisting of neurons. In this subpopulation of cells, both the size of neurons and the number of neurons within the Nissl-defined borders of area $X$ increased in longday towhees. This increase may have resulted from the recruitment of newly generated, large neurons into this nucleus. Alternatively, the increased size of area $X$ may have been associated mainly with an increase in the size of existing neurons. As small neurons increased in size, they could have been recruited into the subpopulation of large neurons that we selectively sampled. We cannot resolve this question with the present data. Area $X$ also increased in volume in the brains of laboratory-reared male blackbirds in breeding condition (Kirn et al., 1989). There are, however, no measures of seasonal variation in neuronal size, spacing, or number within area $X$ of other species with which to compare the data from towhees.

Observations of 17 individually identified wild birds indicated that towhees are age-limited song learners: males do not develop new song types as adults (Ewert, 1978). It therefore appears that dramatic seasonal changes in cellular attributes of the song nuclei HVc, RA, and area X can occur without disrupting existing song repertoires or leading to the learning of new songs by adult male towhees.

\section{Comparative synthesis}

The issue of seasonal variation in song nuclei has now been investigated explicitly in three species in addition to canaries and towhees (see Table 3 for summary). The white-crowned 
sparrow is an age-limited song learner in which males typically sing one song type during the breeding season (Marler, 1970). A white-crown male generally shows little, if any, change in his song in successive breeding seasons (Cunningham and Baker, 1983; Petrinovich and Baptista, 1987). Baker et al. (1984) did not observe seasonal variation in the volumes of HVc and RA in laboratory-reared white-crown males.

The red-winged blackbird is an open-ended learner; males can develop new songs as adults, without forgetting existing songs (Marler et al., 1972; Yasukawa et al., 1980; D. E. Kroodsma, unpublished observations). HVc, area X, and nXII were significantly larger in laboratory-reared male blackbirds on a long-day, as opposed to a short-day, photoperiod. Seasonal changes in HVc, RA, and nXII as large as those reported in males were also observed in wild female blackbirds (Kirn et al., 1989). There is no evidence, however, that female blackbirds learn to sing (T. Armstrong, unpublished observations). The orange bishop (Euplectes franciscanus) is an age-limited learner in which males sing the same single song type each year. In this species, HVc and RA were larger in breeding-condition males (Arai et al., 1989). These studies of sparrows, blackbirds, and bishops did not measure circulating hormone concentrations or cellular attributes of song nuclei.

Although it is necessary to use caution in comparing the results of these different studies, comparisons among the five species discussed above nonetheless reveal that seasonal variation in song nuclei is not limited to species with open-ended song learning (Table 3). The towhee and orange bishop are both agelimitcd lcarncrs, yct both specics show pronounced scasonal variation in song nuclei. Also, this comparison indicates that seasonal variation in brain nuclei cannot be explained readily by whether birds have repertoires of song types. Both the whitecrowned sparrow and the orange bishop sing only one song type, but differ in the absence or presence, respectively, of seasonal changes in song nuclei. Of the five species listed in Table 3, only laboratory-reared white-crowned sparrows fail to show seasonal changes in the size of song nuclei. To verify this observation, it is important that song behavior, circulating hormone levels, and song nuclei be analyzed in wild white-crown males of the nuttalli subspecies, during and after the breeding season.

Comparison of the five species studied thus far leads to a modified view of the relationship between seasonal changes in song nuclei and the ability to learn songs as an adult. Seasonal variation in brain nuclei may arise in a species initially for rcasons unrelated to song learning. Changes in the size or number of hormone-sensitive neurons, for example, might occur in response to seasonal changes in the circulating concentrations of gonadal steroids associated with reproduction. It has been suggested that persistent learning/memory involves long-term modifications of synaptic structure and function (e.g., Kandel and Schwartz, 1982). Learning to produce or perceive new songs may require the formation of entirely new synapses (Nottebohm, 1989). The synaptic plasticity associated with seasonal changes in song nuclei (DeVoogd et al., 1985) may therefore be necessary for the learning of new songs by adult birds. From this perspective, seasonal variation in song nuclei may enable open-ended song learning, but seasonal neural changes may occur in birds without leading to the modification of song by adults. According to this scenario, seasonal changes in song nuclei should be observed in all open-ended song learners, but need not be restricted to such species. Studies of a greater variety of bird species will be necessary to test this hypothesis.

\section{References}

Alvarez-Buylla A, Kirn J, Nottebohm F (1990) Birth of projection neurons in adult avian brain may be related to perceptual or motor learning. Science 249:1444-1446.

Arai O, Taniguchi I, Saito N (1989) Correlation between the size of song control nuclei and plumage color change in orange bishop birds. Neurosci Lett 98:144-148.

Arnold AP, Nottebohm F, Pfaff DW (1976) Hormone accumulating cells in vocal control and other brain regions of the zebra finch (Poephila guttata). J Comp Neurol 155:487-512.

Arnold AP, Bottjer SW, Brenowitz. EA, Nordeen EJ, Nordeen KW (1986) Sexual dimorphism in the neural vocal control system in song birds: ontogeny and phylogeny. Brain Behav Evol 28:22-31.

Baker MC, Bottjer SW, Arnold AP (1984) Sexual dimorphism and lack of seasonal changes in vocal control regions of the white-crowned sparrow brain. Brain Res 295:85-89.

Ball GF, Wingfield JC (1987) Changes in plasma levels of sex steroids in relation to multiple broodedness and nest site density in male starlings. Physiol Zool 60:191-199.

Bohner J, Chaiken M, Ball GF, Marler P (in press) Song acquisition in photosensitive and photorefractory male European starlings. Horm Behav, in press.

Bottjer SW, Miesner EA, Arnold AP (1984) Forebrain lesions disrupt development but not maintenance of song in passerine birds. Science 224:901-903.

Brenowitz EA, Arnold AP (1989) Accumulation of estrogen in a vocal control brain region of a duetting song bird. Brain Res 480:119-125.

Cammermeyer J (1967) Artifactual displacement of neuronal nucleoli in paraffin sections. J Hirnforsch 9:209-224.

Canady R, Kroodsma D, Nottebohm F (1984) Population differences in complexity of a learned skill are correlated with the brain space involved. Proc Natl Acad Sci USA 81:6232-6234.

Cunningham MA, Baker MC (1983) Vocal learning in white-crowned sparrows: sensitive phase and song dialects. Behav Ecol Sociobiol 13: 259-269.

Davis J (1958) Singing behavior and the gonad cycle of the rufoussided towhee. Condor 60:308-336.

DeVoogd TJ, Nottebohm F (1981) Gonadal hormones induce dendritic growth in the adult avian brain. Science 214:202-204.

DeVoogd TJ, Nixdorf B, Nottebohm F (1985) Synaptogenesis and changes in synaptic morphology related to acquisition of a new behavior. Brain Res 329:304-308.

Eales LA (1985) Song learning in zebra finches: some effects of song model availability on what is learnt and when. Anim Behav 33:12931300.

Ewert DN (1978) Song of the rufous-sided towhee on Long Island, New York. PhD thesis, City University of New York.

Gahr M (1990) Delineation of a brain nucleus: comparisons of cytochemical, hodological, and cytoarchitectural views of the song control nucleus HVc of the adult canary. J Comp Neurol 294:30-36.

Gahr M, Fluegge G, Guettinger H-R (1987) Immunocytochemical localization of estrogen-binding neurons in the songbird brain. Brain Res 402:173-177.

Harding C, Follet B (1979) Hormone changes triggered by aggression in a natural population of blackbirds. Science 203:918-920.

Kandel ER, Schwartz JH (1982) Molccular biology of learning: modulation of transmitter release. Science 218:433-443.

Kirn JR, Clower RP, Kroodsma DE, DeVoogd TJ (1989) Song-related brain regions in the red-winged blackbird are affected by sex and season but not repertoire size. J Neurobiol 20:139-163.

Konigsmark BW (1970) The counting of neurons. In: Contemporary research methods in neuroanatomy (Nauta WJH, Ebbeson SO, eds), pp 315-340. New York: Springer.

Konishi M (1989) Birdsong for neurobiologists. Neuron 3:541-549.

Kroodsma DE (1982) Song repertoires: problems in their definition and use. In: Acoustic communication in birds, Vol 2 (Kroodsma DE, Miller EH, eds), pp 25-50. New York: Academic.

Marler P (1970) A comparative approach to vocal learning: song development in white-crowned sparrows. J Comp Physiol Psychol 71: 1-25.

Marler P, Peters S (1982) Subsong and plastic song: their role in the vocal learning process. In: Acoustic communication in birds, Vol 2 (Kroodsma DE, Miller EH, eds), pp 25-50. New York: Academic.

Marler P, Peters S (1987) A sensitive period for song acquisition in 
the song sparrow, Melospiza melodia: a case of age-limited learning. Ethology 76:89-100.

Marler P, Mundinger P, Waser MS, Lutjen A (1972) Effects of acoustical stimulation and deprivation on song development in red-winged blackbirds. Anim Behav 20:586-606.

Nottebohm F (1981) A brain for all seasons: cyclical anatomical changes in song control nuclei of the canary brain. Science 214:1368-1370.

Nottebohm F (1985) Neuronal replacement in adulthood. In: Hope for a new neurology (Nottebohm F, ed), pp 143-162. New York: Annals of the New York Academy of Science.

Nottebohm F (1987) Plasticity in adult avian central nervous system: possible relation between hormones, learning, and brain repair. In: Handbook of physiology (Mountcastle V, chief ed), Sec 1, Higher functions of the nervous system (Plum F, ed), pp 85-108. Baltimore: American Physiological Society, Williams and Wilkins.

Nottebohm F (1989) Hormonal regulation of synapses and cell number in the adult canary brain and its relevance to theories of long-term memory storagc. In: Neural control of reproductive function (Lakoskin JM, Perez-Plo JR, Rassin DK, eds), pp 583-601. New York: Liss.

Nottebohm F, Nottebohm ME (1978) Relationship between song repertoire and age in the canary. Z Tierpsychol 46:298-305.

Nottebohm F, Kasparian S, Pandazis C (1981) Brain space for a learned task. Brain Res 213:99-109.
Nottebohm F, Kelley DB, Paton JA (1982) Connections of vocal control nuclei in the canary telencephalon. J Comp Neurol 207:344357.

Nottebohm F, Nottebohm ME, Crane LA, Wingfield JC (1987) Seasonal changes in gonadal hormone levels of adult male canaries and their relation to song. Behav Neural Biol 47:197-211.

Petrinovich L, Baptista LF (1987) Song development in the whitecrowned sparrow: modification of learned song. Anim. Behav 35: 961-974.

Scharf C, Nottebohm F (1989) Lesions in area $X$ affect song in juvenile but not adult male zebra finches. Soc Neurosci Abstr 15:618.

Sohrabji F, Nordeen EJ, Nordeen KW (1990) Selective impairment of song learning following lesions of a forebrain nucleus in the juvenile zebra finch. Behav Neural Biol 53:51-63.

Suter R, Tolles A, Nottebohm M, Nottebohm F (1990) Bilateral LMAN lesions in adult male canaries affect song in different ways with different latencies. Soc Neurosci Abstr 16:1249.

Wingfield JC, Farner DS (1975) The determination of five steroids in avian plasma by radioimmunoassay and competitive protein binding. Steroids 26:311-327.

Yasukawa K, Blank JL, Patterson CB (1980) Song repertoires and sexual selection in the red-winged blackbird. Behav Ecol Sociobiol 7: 233-238 